\title{
Thyroid Stimulating Hormone Receptor Transcripts in Correlation with Clinical Parameters in Thyroid Carcinoma Patients
}

Tanja Makazlieva ${ }^{1 *}$, Olivija Vaskova ${ }^{1}$, Toni Tripunoski ${ }^{1}$, Sinisha Stojanoski ${ }^{1,2}$, Nevena Manevska ${ }^{1}$, Zlatko Jakovski ${ }^{3}$, Sasho Risteski ${ }^{3}$, Hilda Jovanovic ${ }^{3}$, Aleksandar Eftimov ${ }^{4}$

${ }^{1}$ Institute of Pathophysiology and Nuclear Medicine, Medical Faculty, University Ss Cyril and Methodius, Skopje, Republic of Macedonia; ${ }^{2}$ Medical Faculty, Lazarski University, Warsaw, Poland; ${ }^{3}$ Laboratory for Molecular Genetics, Institute for Forensic Medicine, Criminology and Medical Deontology Medical Faculty, University Ss Cyril and Methodius, Skopje, Republic of Macedonia; ${ }^{4}$ Laboratory of Molecular Pathology, Institute of Pathology Medical Faculty, University Ss Cyril and Methodius, Skopje, Republic of Macedonia

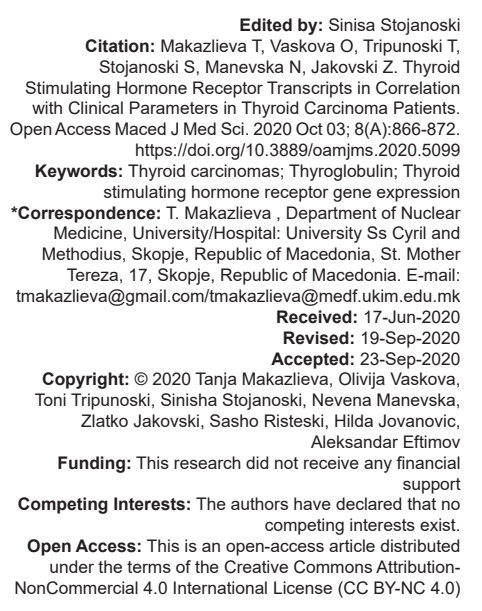

\section{Introduction}

Thyroid tumors are the most common endocrine malignancies, with differentiated thyroid carcinomas (DTCs) representing more than $88 \%$ of all types of thyroid tumors [1], [2], [3], [4]. DTCs preserve expression of TSHR and the previous research found that the lower expression of TSHR was associated with a poor differentiation of thyroid carcinomas and a higher probability for distant metastases [4], [5]. Through TSH stimulation TSHR perform its own function in thyrocyte proliferation, differentiation and normal thyroid development and function. Association of higher expression of TSHR in DTC was described, with the lower expression of the two mesenchymal markers $\mathrm{N}$-cadherin and vimentin, suggesting that the higher expression of TSHR inhibited cell invasion and metastasis through epithelial-mesenchymal transition [5].

Besides standard diagnostic procedures during follow-up suggested by the American and
European thyroid association guidelines [6], [7], new biomarkers in follow-up of DTC could be useful especially in patients with elevated antithyroglobulin antibodies (aTG), limiting usefulness of immunometric chemiluminescent assay in the measurement of serum thyroglobulin (sTg), as well as limiting specificity of sTg value in patients without ablative radioiodine therapy and treated only with lobectomy [8].

New molecular technics enabled evaluation of the expression levels of specific transcripts in peripheral blood and this method was applied in other solid tumors, such as prostate, breast, and colon cancer, as one of the methods in the detection of circulating tumor cells in peripheral blood [9]. The detection of the circulating tumor cells is based on the principle of measurement expression of tumor specific transcripts in the blood sample [9]. Since Ditkoff et al. [10] reported a possible usefulness of RT-PCR molecular technique in the detection of thyroid circulating cells in blood samples as an indicator of metastatic TC, an increased number 
of studies on this issue have been published in the past few years [11], [12], [13].

Using data from the previous investigations in relative quantification of gene expression in other malignancies and the previous experiences from evaluation of thyroid transcripts, we decided to perform a relative gene expression of mRNA-thyrotropin receptor (TSHR) gene in patients with DTC [14], [15]. It is considered that the presence and higher expression of tumor specific transcripts indicate the presence of circulating tumor cells.

We have set as an objective in our study to evaluate the expression of TSHR gene transcripts in patients with DTC, and then to correlate the expression with clinical features: Serum thyroglobulin (sTg) value, total received dose of radioiodine therapy (RAI), initial staging and findings from the whole body scan (WBS), and neck ultrasound (US) of DTC patients.

\section{Materials And Methods}

\section{Subjects}

Blood sampling from 40 patients with DTC was performed. In all patients, surgery and ablation treatment with radioactive ${ }^{131} \mathrm{I}$ were conducted at least 6 months before starting the research. Patients were divided into three groups according to blood levels of sTg and aTg antibodies (CRM 457, Immulite 2000; Siemens, Munich, Bavaria, Germany), US neck examination and findings from WBS, similar to the concept of risk stratification by Tuttle et al. [16]. The first group (TCs - 22 patients), consisted of patients with incomplete structural response to treatment and biochemical relapse of the disease; imaging confirmed metastatic spread or loco-regional relapse and elevated sTg levels > $0.2 \mathrm{ng} / \mathrm{mL}$. The second group (TCb - 6 patients) was patients with incomplete biochemical response and indeterminate response, with only elevated $\mathrm{sTg}>0.2 \mathrm{ng} / \mathrm{mL}$, or elevated aTg levels, without confirmed and known morphological signs for relapse. The third group of patients ( $\mathrm{TCr}-12$ patients) had complete structural and biochemical response to therapy, excellent responders. The thyroid bed and neck lymph nodes were evaluated with ultrasound (US) of the neck with linear transducer $7.5-10 \mathrm{MHz}$. WBS was performed after ablative or therapy dose of radioiodine (RAI). Planar scan and in some cases single-photon emission computed tomography (SPECT/CT) were performed on dual-head gamma camera. Scans were interpreted by two (more than ten years) experienced nuclear medicine physicians. Imaging findings from WBS and neck US were scored: $(0)$ if there was no remnant tissue and enlarged neck lymph nodes and absence of distant metastases, (1) if remnant thyroid tissue was detected, (3) if loco-regional relapse and local neck involved lymph nodes were detected, and (4) if distant metastases were present. Corresponding to the histopathology reports from total 40 patients, four cases were follicular thyroid carcinoma, 25 typical variants of papillary thyroid carcinoma, one papillary thyroid carcinoma in thyroglossal duct cyst, one papillary microcarcinoma, seven follicular variants of papillary thyroid carcinomas, and two Hurtle cell carcinomas. The TNM staging system for DTC developed by the American Joint Committee on Cancer (AJCC) was recorded from the histopathology report, and in 31 of 40 patients, we found detailed description of initial staging according TNM. Of them, 15 patients were classified as Stage I, two patients were Stage II, four patients were Stage III, one patient was Stage IV, five patients were Stage IVa, and four patients were Stage IVc. The study was approved by the Ethics Committee of the Medical Faculty of Ss Cyril and Methodius University, in Skopje, Republic of Macedonia, and a written consent was obtained from all subjects enrolled in the research.

\section{RNA extraction procedure and real-time polymerase}

\section{Chain reaction}

The blood samples were drawn from patients in standard $3 \mathrm{~mL}$ EDTA blood vacutainers; total RNA was extracted using commercially available RNA isolation kit GenElute $^{\mathrm{TM}}$. Total RNA purification kit (Sigma-Aldrich Co. LLC, St. Louis, MO, USA) and isolated total RNA were used for two-step RT-PCRa with ReadyScript ${ }^{\mathrm{TM}}$ cDNA Synthesis Mix kit (Sigma-Aldrich), according to the manufacturer's protocols.

\section{Real-time polymerase chain reaction}

The PCR step was performed using the following primer pairs: TSHR-F 5'-GCT TTT CAG GGA CTA TGC AAT GAA-3' and TSHR-R 5'-AAG GGC AGT GAC ACT GGT TTG AGA-3', targeted to amplify a segment spanning exons 6 to 9 (nucleotides 555-767 or 212 bp) [17]. The ubiquitously expressed GAPDH gene was used to confirm RNA extraction and RT-PCR using primers GAPDH-F 5'-TTC GTC ATG GGT GTG AAC C-3' and GAPDH-R 5'-GAT GAT GTT CTG GAG AGC CC-3', as previously reported [17], [18]. $2 \mu$ of cDNA was added for RT quantitative PCR (qPCR), performed according manufacturer's protocol for Hot FirePol Eva Green qPCR Mix Plus (Rox) PCR master mix (Solis BioDyne, Tartu, Estonia). The reaction mixture for TSHR was incubated at $95^{\circ} \mathrm{C}$ for $15 \mathrm{~min}$, followed by 38 cycles of denaturation at $95^{\circ} \mathrm{C}$ for $15 \mathrm{~s}$, annealing at $62^{\circ} \mathrm{C}$ for $20 \mathrm{~s}$, and elongation at $72^{\circ} \mathrm{C}$ for 20 seconds, and for GAPDH incubated at $95^{\circ} \mathrm{C}$ for $15 \mathrm{~min}$, followed by 38 cycles of denaturation at $95^{\circ} \mathrm{C}$ for 15 seconds, annealing at $57^{\circ} \mathrm{C}$ for $20 \mathrm{~s}$, and elongation at $72^{\circ} \mathrm{C}$ for $20 \mathrm{~s}$. All samples were analyzed in duplicate and in some cases in triplicate. 


\section{Relative quantification method}

Relative quantification was applied by calculating fold change in the gene expression of TSHR target gene, normalized to the endogenous reference gene GAPDH. Cycle threshold (Ct), $\Delta \mathrm{Ct}, \Delta \Delta \mathrm{Ct}$, and normalized relative expression ratio values were calculated according to $2^{-\Delta \Delta \mathrm{Ct}}$ method, by Livak and Schmittgen [14]. According to this method, $\triangle \mathrm{CtTSHR}=$ (average CtTSHR-average CtGAPDH) and then $\Delta \Delta \mathrm{Ct}$ value was calculated using $\Delta \mathrm{Ct}$ value from healthy volunteers $(\mathrm{HC})$, from data published previously by our group [19], or $\Delta \Delta \mathrm{Ct}=[\Delta \mathrm{Ct}(\mathrm{TC})-\Delta \mathrm{Ct}(\mathrm{HC})]$ and later normalized expression ratio $2^{-\Delta \Delta C t}$ was applied for fold change evaluation [14], [15], [19].

\section{Statistical analysis}

Intergroup comparison between average $\Delta \mathrm{Ct}$ $=(T S H R-G A P D H)$ values was performed with MannWhitney U-test. Spearman rank order correlation was performed to measure the direction and strength of the association between mRNA-TSHR and sTg, and $m R N A-T S H R$ and total received dose of RAI, as well as between $m R N A-T S H R$ and initial stage and $m R N A$ TSHR and WBS and neck ultrasound findings.

\section{Results}

In 37 of 40 patients, the expression of $m R N A$ TSHR was detected. Three patients from the TCs group were with undetectable samples for mRNA-TSHR. Descriptive analysis of all 40 patients is presented in Tables 1-3. We detected that TCs patients expressed mRNA-TSHR by a 5.37-fold higher level than $\mathrm{TCr}$ patients, TCb patients expressed mRNA-TSHR by

Table 1: Descriptive analysis of patients with incomplete structural response to treatment and biochemical relapse of the disease (TCs group)

\begin{tabular}{lllll}
\hline TCs Pts & $\Delta$ Ct=TSHR-GAPDH $)$ & $\mathrm{sTg}(\mu \mathrm{g} / \mathrm{L})$ & $\mathrm{RAI}(\mathrm{mCi})$ & Stage (TNM) \\
\hline 1 & 10.99 & 16.1 & 0 & III \\
2 & 12.26 & $>300$ & 300 & IVA \\
3 & 13.14 & 3.51 & 432.1 & $\mathrm{n}^{*}$ \\
4 & Undet. ${ }^{*}$ & 7.73 & 130 & $\mathrm{I}$ \\
5 & 9.43 & 254 & 804 & $\mathrm{n}$ \\
6 & 8.57 & 12.9 & 263 & III \\
7 & 9.58 & 0.38 & 100 & $\mathrm{I}$ \\
8 & 10.41 & 3.3 & 252 & $\mathrm{I}$ \\
9 & 12.69 & 0.19 & 100 & $\mathrm{I}$ \\
10 & 10.61 & 231 & 260 & $\mathrm{n}$ \\
11 & 12.38 & $>300$ & 0 & IVC \\
12 & 12.59 & 0.54 & 286.7 & $\mathrm{n}$ \\
13 & 11.67 & 6.48 & 100 & III \\
14 & 7.47 & 117 & 241 & IV \\
15 & 5.35 & $>300$ & 283.5 & II \\
16 & 9.17 & $>300$ & 250 & $\mathrm{n}{ }^{*}$ \\
17 & 9.56 & 43.7 & 0 & IVA \\
18 & 6.68 & $>300$ & 229 & IVC \\
19 & 4.66 & 84 & 0 & IVA \\
20 & 5.53 & $>300$ & 0 & I \\
21 & Undet. ${ }^{*}$ & $>300$ & 0 & IVC \\
22 & Undet. & $>300$ & 100 & IVC \\
\hline${ }^{*}$ Undet: Undetectable expression levels of the $m R N A-T S H R,{ }^{*}$ n: Missing data about initial stage of the \\
diseas
\end{tabular}

Table 2: Descriptive analysis of patients with incomplete biochemical response to treatment or indeterminate response (TCb group)

\begin{tabular}{lllll}
\hline TCb Pts & $\Delta \mathrm{Ct}=\mathrm{TSHR}-\mathrm{GAPDH})$ & $\mathrm{sTg}(\mu \mathrm{g} / \mathrm{L})$ & $\mathrm{RAl}(\mathrm{mCi})$ & Stage $(\mathrm{TNM})$ \\
\hline 1 & 10.77 & $<0.2$ & 50 & $\mathrm{I}$ \\
2 & 12.56 & 0.5 & 102 & $\mathrm{IVA}$ \\
3 & 5.63 & 0.26 & 0 & $\mathrm{I}$ \\
4 & 10.31 & 0.43 & 105 & $\mathrm{I}$ \\
5 & 4.15 & 2.5 & 0 & $\mathrm{I}$ \\
6 & 9.94 & 0.4 & 103 & $\mathrm{n}^{*}$ \\
\hline${ }^{*} \mathrm{n}:$ Missing data about initial stage of the disease. & & &
\end{tabular}

an 8.88-fold higher level than $\mathrm{TCr}$ patients, as was previously reported in our previous study [19].

Table 3: Descriptive analysis of patients with excellent response to treatment (TCr)

\begin{tabular}{lllll}
\hline TCr Pts & $\Delta \mathrm{Ct}=(\mathrm{TSHR}-\mathrm{GAPDH})$ & $\mathrm{sTg}(\mu \mathrm{g} / \mathrm{L})$ & $\mathrm{RAl}(\mathrm{mCi})$ & Stage $(\mathrm{TNM})$ \\
\hline 1 & 11.21 & $<0.2$ & 100 & IVA \\
2 & 17.21 & $<0.2$ & 102 & $\mathrm{I}$ \\
3 & 11.89 & $<0.2$ & 94 & ${ }^{\mathrm{n}}$ \\
4 & 11.015 & $<0.2$ & 87.3 & $\mathrm{n}$ \\
5 & 12.87 & $<0.2$ & 100 & $\mathrm{I}$ \\
6 & 11.20 & $<0.2$ & 100 & $\mathrm{I}$ \\
7 & 10.93 & $<0.2$ & 0 & $\mathrm{n}$ \\
8 & 10.60 & $<0.2$ & 243.8 & $\mathrm{III}$ \\
9 & 12.37 & $<0.2$ & 113 & $\mathrm{I}$ \\
10 & 12.22 & $<0.2$ & 100 & $\mathrm{II}$ \\
11 & 11.11 & $<0.2$ & 100 & $\mathrm{I}$ \\
12 & 11.91 & $<0.2$ & 99.5 & $\mathrm{I}$ \\
\hline${ }^{*}$ n: Missing & & &
\end{tabular}

Further intergroup comparison between average $\Delta \mathrm{Ct}=(T S H R-G A P D H)$ values was performed and a significant difference was detected between TCs and $\mathrm{TCr}$ group (Mann-Whitney U-test: $Z=-2.231$, p 0.026) and TCb and TCr group (Mann-Whitney U-test: $Z=-2.341, p=0.019)$ (Figure 1).

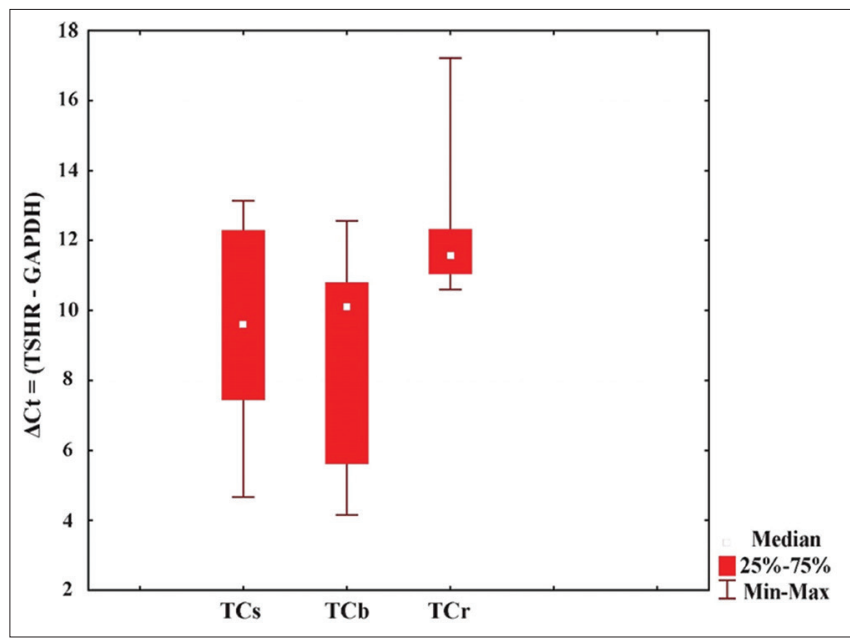

Figure 1: Intergroup comparison between average $\Delta C t=(T S H R-$ $G A P D H)$ values. Range of $\triangle C t=(T S H R-G A P D H)$ values in three groups, patients with incomplete structural response to treatment and biochemical relapse of the disease or imaging confirmed metastatic spread or loco-regional relapse and elevated sTg levels, $>0.2 \mathrm{ng} / \mathrm{mL}$ (TCs patients); second group was patients with incomplete biochemical response and indeterminate response, with only elevated $s T g(>0.2 \mathrm{ng} / \mathrm{mL})$, or elevated aTg levels, without confirmed and known morphological signs for relapse (TCb patients); third group of patients had complete structural and biochemical response to therapy, excellent responders (TCr). Significant difference in average $\Delta C t=(T S H R-G A P D H)$ values was detected between $T C s$ and $T C r$ group (Mann-Whitney U-test: $Z=-2.231, p=0.026$ ) and TCb and TCr group (Mann-Whitney U-test: $Z=-2.341, p=0.019$ )

Correlation between $\mathrm{sTg}$ and $\Delta \mathrm{Ct}=(T S H R$ - GAPDH) for all three groups of patients showed a 
significant negative correlation with Spearman Rank Order Correlation $(\mathrm{R}=-0.475 p<0.05)$ (Figure 2). This finding suggest that the increased $s T g$ value correlated with the lower value of $\triangle \mathrm{Ct}=(T S H R-G A P D H)$ for $T S H R$ gene, or higher expression of the evaluated transcripts.

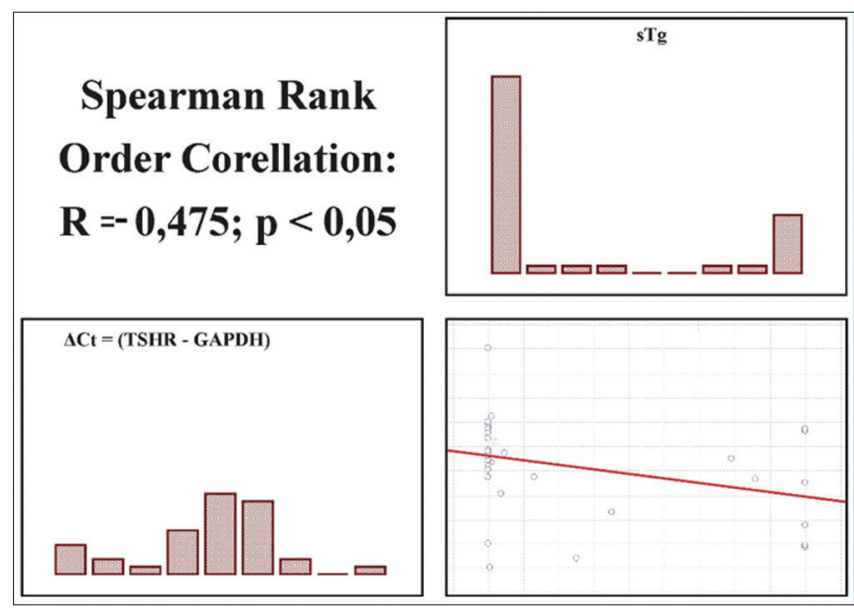

Figure 2: Correlation between $s T g$ and $\triangle C t=(T S H R-G A P D H)$ for all three groups of patients. STg values were correlated with $\Delta C t=(T S H R-G A P D H)$ values from all patients using Spearman Rank Order Correlation. Results showed significant negative correlation $(R=-0.475 p<0.05)$.

The analysis of the correlation between RAI and $\Delta \mathrm{Ct}=(T S H R-G A P D H)$ showed a weak nonsignificant positive correlation with Spearman Rank Order Correlation $(R=0.114, p>0.05)$ (Figure 3). Data showed that with increase of the total received RAI therapy, there was a non-significant increase in the $\Delta \mathrm{Ct}=(T S H R-G A P D H)$ for TSHR gene, or increased $\mathrm{RAl}$ dose correlated with the lower expression levels of transcripts for TSHR gene.

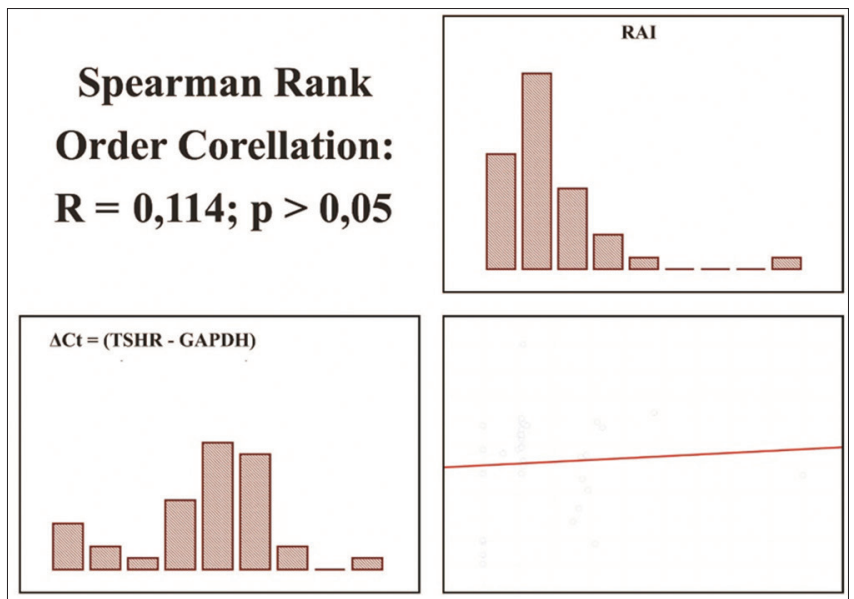

Figure 3: Correlation between received total dose of $R A I(m C i)$ and value for $\Delta C t=(T S H R-G A P D H)$ for TSHR. Received doses of radioiodine therapy in milliCuries were correlated with $\Delta C t=(T S H R$ - GAPDH) values using Spearman Rank Order Correlation. Results showed weak non-significant positive correlation $(R=0.114$, $p>0.05)$.

Correlation between initial stage of the disease according to TNM staging and $\Delta C t=(T S H R$ $G A P D H)$ revealed non-significant negative correlation, with Spearman Rank Order Correlation $(R=-0.0009$, $p>0.05$ ) (Figure 4). This means that with increase of

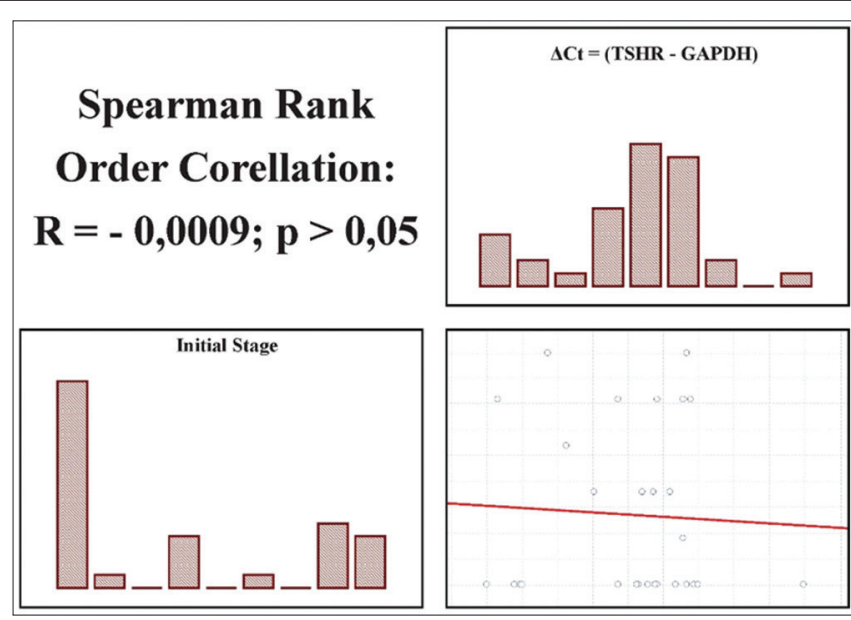

Figure 4: Correlation between initial stage and $\Delta C t=(T S H R$ $G A P D H)$. Initial stages of the disease according TNM staging were correlated with $\triangle C t=(T S H R-G A P D H)$ using Spearman Rank Order Correlation. Results revealed non-significant negative correlation $(R=-0.0009, p>0.05)$

the initial stage of the disease, $\Delta \mathrm{Ct}=(T S H R-G A P D H)$ value was non-significantly lowered, or increase expression of the transcripts of the TSHR gene.

Final analysis in our study was correlation between WBS/US findings and $\Delta C t=(T S H R-G A P D H)$, resulting with significant a moderate negative correlation using Spearman Rank Order Correlation $(R=-0.321, p<0.05)$ (Figure 5$)$. Increase of the score from the findings from WBS/US correlated with significant lowering of the $\triangle \mathrm{Ct}=(T S H R-G A P D H)$, or increase of the score was associated with a significant increase of the expression level of TSHR gene transcripts.

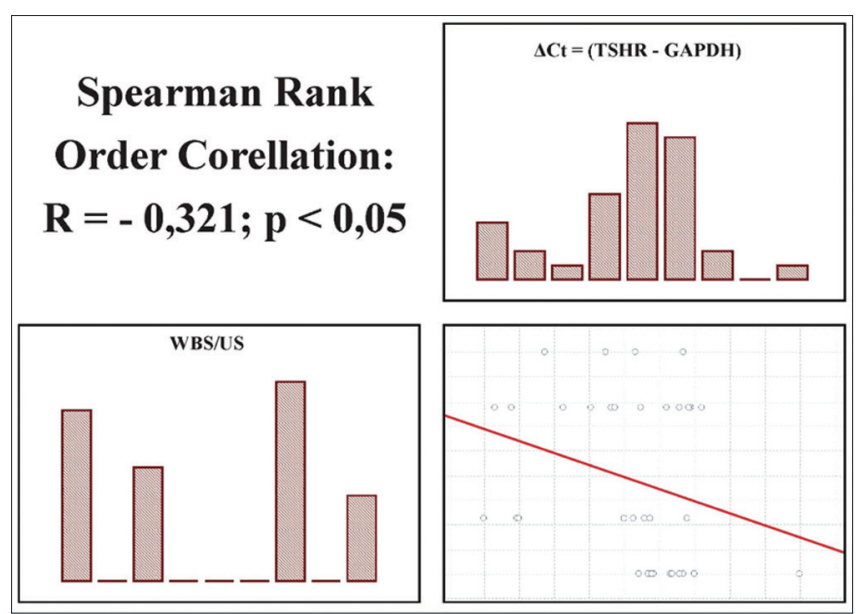

Figure 5: Correlation between WBS/US findings and $\Delta C t=(T S H R$ - GAPDH). Radioiodine WBS were analyzed and neck ultrasound examinations were performed and findings were scored with: $(0)$ if there was no remnant tissue and enlarged neck lymph nodes and absence of distant metastases, (1) if remnant thyroid tissue was detected, (3) if loco-regional relapse and local neck involved lymph nodes were detected, and (4) if distant metastases were present and those scores were correlated with $\triangle C t=(T S H R-G A P D H)$ using Spearman Rank Order Correlation. Results revealed significant moderate negative correlation $(R=-0.321, p<0.05)$. 


\section{Discussion}

Data from our analysis revealed a higher expression level of $m R N A-T S H R$ in peripheral blood of TCs and TCb compared to TCr group of patients. In only three samples from all TCs patients, expression levels were undetectable. This finding may be due to dedifferentiation of tumor in the TCs group of patients and low expression of the evaluated transcripts for the target genes. Correlation of $\Delta \mathrm{Ct}$ value for TSHR gene with sTg level indicated a significant negative correlation, or in other words, elevation of sTg value correlated with an increase in the expression of $m R N A-T S H R$. Increase in expression of mRNA$T S H R$ results in lowering $\Delta \mathrm{Ct}$ value representing the difference between threshold cycles for the amplicons for target gene and reference gene. In DTC patients besides STg level, neck US and WBS are an important and standard part of the follow-up routine. Evaluated association between US/WBS findings and $\Delta$ Ct value for $T S H R$ gene also revealed a significant negative correlation, which means extensiveness of the loco-regional status or distant metastatic state confirmed with imaging modalities correlated with higher expression of mRNA-TSHR. Ringel et al. [20] evaluated the expression of $m R N A-T g$ and they found that quantitative detection of circulating $m R N A-T g$ corresponded with the finding from last radioiodine WBS. They analyzed and found a positive connection of TSH value and expression of $m R N A-T g$ in patients with DTC, and although the exact mechanism was not known, they suggested that this relation was due to an increased $\mathrm{Tg}$ gene transcription under stimulation of TSH [20]. The need of new molecular biomarkers in diagnosis and follow-up of DTC is important in patients with elevated aTg antibodies and in patients with lobectomy, without ablative radioiodine therapy, which is recommended in low-risk group of patients according to the new ATA 2015 guidelines [8], [16]. The detection of mRNA of Tg gene was first introduced by Ditkoff et al. and the results were encouraging [9], [10], initiating many researchers to work in this field, but methodology varied significantly among research groups in respect of used primers, number of cycles, selection of reference gene, and quantification. In 2002, Gupta et al. [17] concluded that mRNA-TSHR could be tumor marker for DTC patients [13]. In 2004, Chinnappa et al. [18] found that DTC patients had a higher rate of $m R N A-T S H R$ expression in the peripheral blood than healthy individuals [14]. Wagner et al. [21] using RT-PCR detected a higher level of $m R N A-T S H R$ in patients with benign thyroid nodules. We applied the semi-quantitative analysis using $2^{-\Delta \Delta C}$ method by Livak [14] in the previous research including healthy individuals and DTC patients and detected significantly higher expression in TCs and TCb group of patients compared to healthy control group [19]. Our further analysis was aimed at correlation of expression of $m R N A-T S H R$ with $\mathrm{sTg}$ values, initial staging, US/ WBS findings and total received RAI therapy. Our findings revealed that expression of the transcripts corresponded with clinical and laboratory findings in the evaluated patients. On the other hand, we found non-significant correlation with the initial stage of the disease and expression levels. This might be due to a great difference in the follow-up period of patients which varied from only 1 month to 405 months from diagnosis till including in the study. Furthermore, there is a possibility of the lower expression of the transcripts for TSHR gene in more aggressive variants, or development of dedifferentiation of the tumor in the evolution of the disease. In light of this explanation is the non-significant positive correlation of $\Delta \mathrm{Ct}$ with the total dose of RAl therapy, or increased dose correlated non-significantly with the lower expression of $m R N A-T S H R$.

Mira Milas et al. have published several studies comprising the largest number of patients with expression of $m R N K-T S H R$ in DTC cases and found that expression levels were lower or undetectable in more aggressive forms of thyroid carcinomas and dedifferentiation, or mutation of the evaluated gene was pointed as a possible reason [22]. Qiu et al. [23] investigated the possible role of mRNA$T S H R$ measurement in peripheral blood preoperative detection of microcarcinomas in suspicious nodules smaller than $1 \mathrm{~cm}$. They evaluated mRNA-TSHR in peripheral blood in healthy volunteers and in benign and malignant papillary microcarcinomas and mRNA-TSHR correctly classified $77.8 \%$ of patients preoperatively (sensitivity $=76.5 \%$; specificity $=79.4 \%$ ). Combining $m R N A-T S H R$ and US examination correctly detected $97.1 \%$ of PTMC and could spare surgery in $86.8 \%$ of patients with benign thyroid nodules [23]. Riming Liu et al. [24] correlated expression levels of mRNA-TSHR, and besides significantly higher expression of mRNA$T S H R$ preoperatively in patients with papillary thyroid carcinoma compared to patients with benign nodules, they found that PTC patients' pre-operative mRNA-TSHR expression level was associated with age, histological type, capsular invasion status, lymph node metastasis status, and BRAFV600E mutation status, but not with gender, tumor size, number of cancer foci, or presence of autoimmune thyroiditis [24].

\section{Conclusion}

Data from our research revealed a higher expression level of $m R N A-T S H R$ in peripheral blood of TCs and TCb compared to TCr group patients. Our findings revealed a significant correlation between 
mRNA-TSHR and sTg and US/WBS, or expression of the transcripts corresponded with clinical and laboratory findings in the evaluated patients. On the other hand, we found no significant correlation with an initial stage of the disease and expression levels. Further studies with larger number of subjects included, preoperatively and postoperatively, as well as absolute quantification of the transcripts are needed for complete understanding of the possible usefulness of $m R N A-T S H R$ as a potential biomarker in DTCs.

\section{Acknowledgments}

This work was supported both in equipment and guidance by the Laboratory for molecular genetics at Institute for Forensic Medicine and Laboratory of molecular pathology and Institute of Pathophysiology and Nuclear medicine.

\section{Statement of Ethics}

The study was approved by the Ethics Committee of the Medical Faculty of Ss Cyril and Methodius University, in Skopje, Republic of Macedonia, and a written consent was obtained from all subjects enrolled in the research.

\section{Author Contributions}

Makazlieva T, Jakovski Z, and Eftimov A constructed the study design, Vaskova $O$ has been involved in revising the manuscript for important intellectual outcome; Tripunoski T, Jovanovic $\mathrm{H}$, and Risteski $S$ have given substantial contributions to conception and design; Makazlieva $\mathrm{T}$ and Eftimov A have given substantial contribution to acquisition, analysis, and interpretation of data; Makazlieva T, Stojanoski S, and Manevska $\mathrm{N}$ have been involved in drafting the manuscript and looking for the most suitable references. All authors read and approved the final manuscript.

\section{References}

1. De Groot LJ, Larsen PR, Hennemann G. The Thyroid and its Diseases. $6^{\text {th }}$ ed. London, United Kingdom: Churchill

\section{Livingstone; 1995.}

2. Scopa CD. Histopathology of thyroid tumors. An overview. Hormones. 2004;3(2):100-10. https://doi.org/10.14310/ horm.2002.11118

PMid:16982584

3. Lloyd RV, Buehler D, Khanafshar E. Papillary thyroid carcinoma variants. Head Neck Pathol. 2011;5(1):51-6. https://doi. org/10.1007/s12105-010-0236-9

PMid:21221869

4. Schumberger M, Pacini F, Tutle RM. Thyroid Tumors. $4^{\text {th }}$ ed Paris: Institute Medico-Educatif; 2015.

5. Liu T, Men Q, Su X, Chen W, Zou L, Li Q, et al. Downregulated expression of TSHR is associated with distant metastasis in thyroid cancer. Oncol Lett. 2017;14(6):7506-12. https://doi. org/10.3892/ol.2017.7122

PMid:29344196

6. Pacini F, Castagna G, Brilli L, Pentheroudakis G. Thyroid cancer: ESMO clinical practice guidelines for diagnosis, treatment and follow-up. Ann Oncol. 2012;23(Suppl 7):110-9. https://doi. org/10.1093/annonc/mds230

PMid:22997443

7. Alexander EK, Bible KC, Doherty GM, Mandel SJ, Nikiforov YE, Pacini $\mathrm{F}$, et al. American Thyroid Association Management Guidelines for Adult Patients with Thyroid Nodules and Differentiated Thyroid Cancer. Falls Church, Virginia: American Thyroid Association; 2015.

8. Teama SH, Agwa SH, Fawzy A, Sayed MM, Ibrahim WA, Eid YM Molecular detection of circulating thyroid specific transcripts (TSHR/Tg-mRNAs) in thyroid cancer patients: Their diagnostic significance. Egypt J Med Hum Genet. 2011;12:201-9. https:// doi.org/10.1016/j.ejmhg.2011.08.002

9. Andergassen $U$, Zebisch M, Kölbl AC, König A, Heublein S Schröder L, et al. Real-time qPCR-based detection of circulating tumor cells from blood samples of adjuvant breast cancer patients: A preliminary study. Breast Care (Basel). 2016;11(3):194-8. https://doi.org/10.1159/000447041 PMid:27493620

10. Ditkoff BA, Marvin MR, Yemul S, Shi YJ, Chabot J, Feind C et al. Detection of circulating thyroid cells in peripheral blood. Surgery. 1996;120(6):959-65. https://doi.org/10.1016/ s0039-6060(96)80041-9 PMid:8957481

11. Badulescu IC, Barbus E, Piciu D. Circulating tumor cells in thyroid carcinoma-The prognostic role of this biomarker. Review of the literature. Clujul Med. 2017;90(3):256-61. https://doi. org/10.15386/cjmed-712

PMid:28781520

12. Barzon L, Boscaro M, Paenti M, Taccaliti A, Palu G. Evaluation of circulating thyroid-specific transcripts as markers of thyroid cancer relapse. Int J Cancer. 2004;110(6):914-20. https://doi. org/10.1002/ijc.20182

PMid: 15170676

13. Wingo ST, Ringel MD, Anderson JS, Patel AD, Lukes YD, Djuh $Y Y$, et al. Quantitative reverse transcription-PCR measurement of thyroglobulin mRNA in peripheral blood of healthy subjects. Clin Chem. 1999;45(6 Pt 1):785-9. https://doi. org/10.1093/clinchem/45.6.785 PMid:10351986

14. Livak KJ, Schmittgen TD. Analysis of relative gene expression data using real-time quantitative PCR and the 2(-Delta Delta $C(T)$ ) method. Methods. 2001;25(4):402-8. https://doi. org/10.1006/meth.2001.1262 PMid:11846609

15. Rao X, Huang $X$, Zhou Z, Lin X. An improvement of the $2^{\wedge}$ (-delta delta CT) method for quantitative real-time polymerase 
chain reaction data analysis. Biostat Bioinforma Biomath. 2013;3(3):71-85.

\section{PMid:25558171}

16. Tuttle RM, Tala H, Shah J, Leboeuf R, Ghossein R, Gonen M, et al. Estimating risk of recurrence in differentiated thyroid cancer after total thyroidectomy and radioactive iodine remnant ablation: Using response to therapy variables to modify the initial risk estimates predicted by the new American thyroid association staging system. Thyroid. 2010;20(12):1341-9. https://doi.org/10.1089/thy.2010.0178

PMid:21034228

17. Gupta MK, Taguba L, Arciaga R, Siperstein A, Faiman C, Mehta A, et al. Detection of circulating thyroid cells by reverse transcription-PCR for thyroid-stimulating hormone receptor and thyroglobulin: The importance of primer selection. Clin Chem. 2002;48(10):1862-5. https://doi.org/10.1093/ clinchem/48.10.1862

18. Chinnappa P, Taguba L, Arciaga R, Faiman C, Siperstein A, Mehta AE. Detection of thyrotropin-receptor messenger ribonucleic acid (mRNA) and thyroglobulin mRNA transcripts in peripheral blood of patients with thyroid disease: Sensitive and specific markers for thyroid cancer. J Clin Endocrinol Metab. 2004;89(8):3705-9. https://doi.org/10.1210/jc.2003-031967 PMid:15292293

19. Makazlieva T, Eftimov A, Vaskova O, Tripunoski T, Miladinova D, Risteski $\mathrm{S}$, et al. Determining specific thyroid transcripts in peripheral blood: A single center study experience. Balkan $\mathrm{J}$ Med Genet. 2018;21(2):13-20. https://doi.org/10.2478/ bjmg-2018-0015 PMid:30984519

20. Ringel MD, Balducci-Silano PL, Anderson JS, Spencer CA,
Silverman J, Sparling $\mathrm{YH}$, et al. Quantitative reverse transcription-PCR of circulating thyroglobulin messenger ribonucleic acid for monitoring patients with thyroid carcinoma. J Clin Endocrinol Metab. 1999;84(11):4037-42. https://doi. org/10.1210/jc.84.11.4037

PMid: 10566646

21. Wagner K, Arciaga R, Siperstein A, Milas M, Warshawsky I, Sethu S, et al. Thyrotropin receptor/thyroglobulin messenger ribonucleic acid in peripheral blood and fine-needle aspiration cytology: Diagnostic synergy for detecting thyroid cancer. J Clin Endocrinol Metab. 2005;90:1921-24. https://doi.org/10.1210/ jc.2004-1793

PMid:15687333

22. Milas M, Shin J, Gupta M, Novosel T, Nasr C, Brainard J, et al. Circulating thyreotropin receptor mRNA as a novel marker of thyroid cancer: Clinical applications learned from 1758 samples. Ann Surg. 2010;252(4):643-51.

PMid:20881771

23. Quu J, Zhang Y, Guo X, Zeng F, Zhao C, Qiu, X, et al. Quantitation of thyroid-stimulating hormone receptor mRNA with real-time PCR for early diagnosis of papillary thyroid microcarcinoma. Neoplasm. 2010;57(4):360-4.

PMid:20429628

24. Riming L, Shaolong $H$, Hua $Z$, Jihong $M$, Xincheng $L$, Jie $X$, et al. Correlation of thyroid stimulating hormone receptor mRNA expression levels in peripheral blood with undesirable clinicopathological features in papillary thyroid carcinoma patients. Oncotarget. 2017;8(43):74129-38. https://doi. org/10.18632/oncotarget.18273

PMid:29088773 